
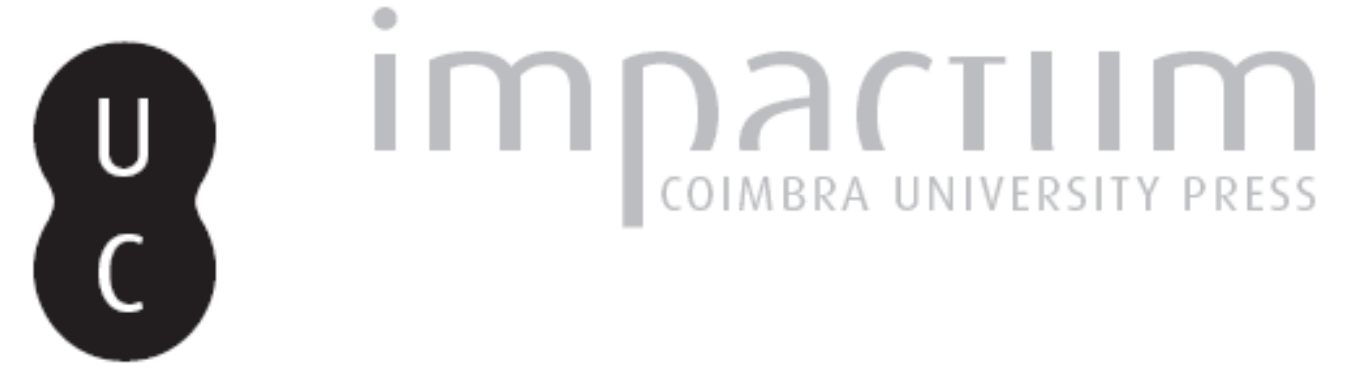

\title{
Arquivos salgados mas não conservados: memória documental dos organismos corporativos e de coordenação económica das pescas do Estado Novo
}

Autor(es): $\quad$ Garrido, Álvaro

Publicado por: Imprensa da Universidade de Coimbra

URL persistente:

URl:http://hdl.handle.net/10316.2/45012

DOI:

DOI:https://doi.org/10.14195/0870-4147_38_17

Accessed : $\quad$ 26-Apr-2023 15:44:05

A navegação consulta e descarregamento dos títulos inseridos nas Bibliotecas Digitais UC Digitalis, UC Pombalina e UC Impactum, pressupõem a aceitação plena e sem reservas dos Termos e Condições de Uso destas Bibliotecas Digitais, disponíveis em https://digitalis.uc.pt/pt-pt/termos.

Conforme exposto nos referidos Termos e Condições de Uso, o descarregamento de títulos de acesso restrito requer uma licença válida de autorização devendo o utilizador aceder ao(s) documento(s) a partir de um endereço de IP da instituição detentora da supramencionada licença.

Ao utilizador é apenas permitido o descarregamento para uso pessoal, pelo que o emprego do(s) título(s) descarregado(s) para outro fim, designadamente comercial, carece de autorização do respetivo autor ou editor da obra.

Na medida em que todas as obras da UC Digitalis se encontram protegidas pelo Código do Direito de Autor e Direitos Conexos e demais legislação aplicável, toda a cópia, parcial ou total, deste documento, nos casos em que é legalmente admitida, deverá conter ou fazer-se acompanhar por este aviso.

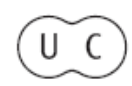



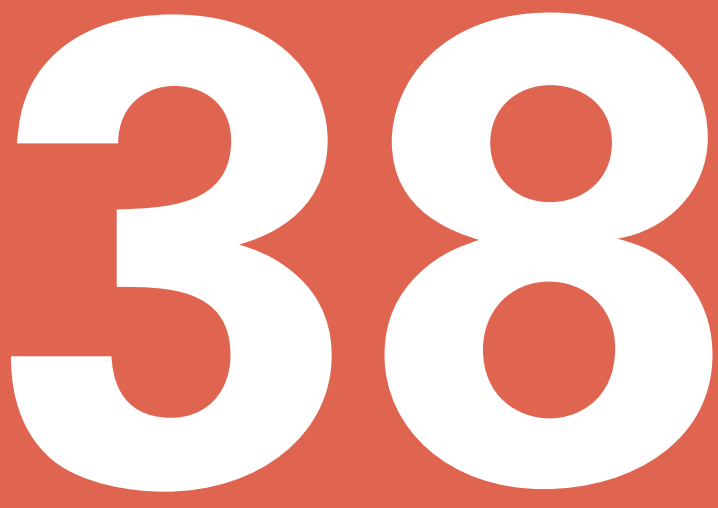

\section{Revista Portuguesa de História}

Faculdade de Letras da Universidade de Coimbra Instituto de História Económica e Social

Coimbra 08 
Revista Portuguesa de História

t. XXXVIII (2006)

pp. 465-482

\title{
Arquivos salgados mas não conservados Memória documental dos organismos corporativos e de coordenação económica das pescas do Estado Novo
}

\author{
Álvaro Garrido \\ Faculdade de Economia da Universidade de Coimbra
}

CEIS 20

\section{Introdução}

Na memória de um historiador há momentos particularmente inscritos. Por sugestão do nosso imaginário profissional ou por coacção simbólica da Academia, tendemos a gravar, quase a sacralizar, aqueles instantes que identificamos com a descoberta de um extenso fundo documental, presumivelmente inédito e sobre o qual nos detivemos durante anos, aplicando com aparente vagar os métodos canónicos da nossa disciplina. Não raro, esse encanto primordial e a presunção de que, também nós, fôramos capazes de resgatar de uma cave sombria um "arquivo" indispensável para o avanço da historiografia contemporânea, cede a um previsível elenco de fins instrumentais: ler expeditamente os índices das pastas ou dos dispersos papéis cujo volume nos parece condenar a uma interminável prova de resistência; discernir um sentido qualquer, de preferência um princípio ordenador, no imenso acervo de fontes que se nos depara; ler e interpretar, sem descuido das intertextualidades que a hermenêutica pós-moderna recomenda; descrever, explicar e desconstruir. Enfim, redigir.

Por extenuante e destinado a consumir-se num ritual efémero para confirmar um investigador, o "processo de doutoramento" - prova de fundo, cujo figurino 
está, por moda, condenado à extinção - cedo desfaz no "candidato" o velho mito da historiografia romântica, atribuído a Jules Michelet, segundo o qual o historiador, empenhado em compor uma bela intriga de tempos que não viveu, exerce a sua imaginação visionária nos arquivos.

Esta nota preambular, reflexiva mas obviamente datada, supõe uma narrativa autobiográfica pouco original para os historiadores. Por isso, de pouco importa contá-la, a não ser num sucinto testemunho da nossa história de encontro com os fundos de arquivo dos extintos organismos corporativos e de coordenação económica das pescas do período salazarista ${ }^{1}$, caso singular que poderá interessar a debates mais amplos nos campos historiográfico e da epistemologia das fontes para a história do Estado Novo.

Sem surpresa, a narrativa que arquivamos na nossa memória individual, tipifica os problemas de acesso dos historiadores do "século XX português" à imensa lista de fundos documentais que ficaram algures, perdidos e mal conservados, num insuspeito armazém ou hangar em desuso, à espera do desfecho de intermináveis processos de liquidação das velhas instituições da "economia corporativa"2.

Mais interessante do que exprimir os habituais e justificados lamentos, será fazer uso deste exemplo para reflectir sobre a natureza dominante das fontes que habitam neste género de "arquivos" e sobre as vicissitudes do uso

\footnotetext{
1 Quando nos referimos aos "organismos das pescas do Estado Novo" reportamo-nos a uma imensa teia de instituições corporativas e puramente estatais, composta por cinco grémios (e respectivas mútuas de seguros e cooperativas de aprestos) e dois organismos de coordenação económica, a Comissão Reguladora do Comércio de Bacalhau (CRCB) e o Instituto Português de Conservas de Peixe. A esta rede administrativa bipolar - organização corporativa de um lado, coordenação económica, do outro - acrescia a rede de Casas dos Pescadores e a sua entidade federativa, a Junta Central das Casas dos Pescadores, e ainda uma série dispersa de "sindicatos nacionais" de profissionais de bordo. No âmbito da organização corporativa havia ainda uns poucos organismos técnicos e consultivos, a exemplo do Instituto de Biologia Marítima e do Gabinete de Estudos das Pescas. Neste ensaio, apenas tomaremos em consideração a CRCB e o Grémio dos Armadores de Navios de Pesca do Bacalhau, cujos arquivos foram centrais na nossa investigação de doutoramento. Para um organigrama da administração das pescas criada pelos governos de Salazar, vide A. Garrido, O Estado Novo e a Campanha do Bacalhau, Lisboa, Círculo de Leitores, 2004, p. 251.

2 Por imprecisão conceptual, tende a classificar-se toda a herança reguladora e dirigista do Estado Novo como património institucional da "economia corporativa", abarcando na expressão os próprios organismos de coordenação económica que, na sua maioria, sobreviveram à extinção da organização corporativa que ocorreu em 1974-75. Neste escrito, faremos uso da expressão "economia corporativa" numa acepção lata. Assim, o conceito remete para a experiência histórica do corporativismo português, nas suas contradições e desvios à matriz teórica e doutrinal imaginada em finais de Oitocentos e no primeiro quartel do século XX, como uma espécie de "terceira via" capaz de resolver (ou reprimir) a "questão social" e de se opor à crise do Estado liberal.
} 
científico dessa memória documental para o estudo dos processos de regulação e direcção impostos pelo Estado Novo aos sectores mais relevantes da "economia nacional". Por outras palavras, a nossa história de sal e burocracia só tomará algum sentido útil se convocada para um debate mais largo: a propósito das relações entre economia e política no período salazarista; sobre economia e instituições, discutindo as relações entre público e privado e o processo de transição da "era liberal" para o "capitalismo de organização" anunciado pelos doutrinadores do sistema corporativo.

O itinerário que propomos é necessariamente curto.

Em primeiro lugar, a própria narrativa do encontro entre sujeito e objecto, quando afortunadamente se nos deparou um arquivo salgado mas não conservado, que prometia revelar-nos o essencial da intervenção do Estado autoritário no abastecimento de bacalhau entre 1934 e 1974. Numa segunda etapa, faremos uma periodização do organismo de coordenação económica, a Comissão Reguladora do Comércio de Bacalhau (CRCB), cujos fins oficiais e ciclos de vida permitirão supor a quantidade e a natureza da memória documental que os seus serviços organizaram e deixaram. Num terceiro ponto, caracterizaremos os fundos documentais legados por esse organismo estatal de inspiração fascista centrando a nossa discussão na natureza dominante das fontes e no carácter totalizante da informação que se presta à consulta dos historiadores.

Por último, partindo da nossa experiência neste labirinto de meta-fontes, proporemos uma agenda de problemas de investigação cujo exame tenderá a revalorizar a importância do "estudo arqueológico" das instituições para a historiografia do Estado Novo, caminho que implica um diálogo mais fluente entre historiadores e arquivistas.

\section{O imaginário histórico da pesca do bacalhau e os seus ardis}

Contrariando o imaginário prevalecente nas memórias sociais de grupos cujas vidas se ligaram ao mar e o próprio cliché historicista, Portugal foi, desde o termo do século XVI, um grande importador de bacalhau salgado seco, jamais uma potência pesqueira. Embora tenha sido um país pioneiro na "grande pesca" nos bancos setentrionais do Atlântico, seja nos alvores de Quinhentos (no tempo mítico do achamento da Terra Nova por navegadores portugueses), seja no terceiro quartel do século XX (no auge da "campanha do bacalhau" promovida pelo Estado $\mathrm{Novo}^{3}$ ), Portugal nunca dominou a pescaria. Porém,

3 Sobre a "campanha do bacalhau", a sua génese e infusão nas estruturas vitais do Estado Novo, vide o nosso livro, O Estado Novo e a Campanha do Bacalhau, cit., em especial, pp. 67-144. 
embora pequeno e estreito - por razões de ordem cultural e geográfica e por influência de factores económicos e sociais -, o Reino mais litorâneo da Europa meridional cedo se tornou o maior mercado consumidor desse peixe salgado e seco, capturado em longas e cruéis campanhas nos mares do Atlântico Noroeste.

No começo de Oitocentos, a condição histórica de Portugal como grande importador de bacalhau começou a ser glosada por "economistas" e por outras elites ilustradas que a declararam um sintoma de fraqueza do Estado e de subordinação ao interesse de potências marítimas e mercantis estrangeiras. Durante vários séculos, ao certo entre finais de Seiscentos e os anos cinquenta do século XX, a insuficiência crónica da pesca por navios armados em portos portugueses e a flutuação dos contingentes de produção nacional conjugou-se com a pressão dos interesses do comércio importador. A acesa disputa do mercado português pelos grandes exportadores, cujos agentes britânicos sempre se moveram nas praças de Lisboa e do Porto e amiúde o fizeram com recurso a práticas de dumping que "empatavam" a venda do "bacalhau português", tornou-se um factor estrutural de perturbação da dinâmica do abastecimento.

Exceptuando certas intervenções dos poderes municipais na regulação e condicionamento das importações, de que há registo em séculos recuados, o interesse do Estado pelo "problema do bacalhau" só se concretiza no plano jurídico em meados de 1934. É esse o momento em que o "Estado ditador de víveres" que Salazar reclamara num escrito universitário de 1918 se exprime na criação da $\mathrm{CRCB}^{4}$. Este organismo de coordenação económica de inspiração fascista - o arquétipo foi colhido nos enti di cordinamento economico que Mussolini impôs para conduzir a campanha do arroz - foi incumbido de dirigir e fiscalizar, verticalmente, o abastecimento de bacalhau. Imaginado com grandeza de propósitos, o seu perfil obedeceu a um esquema proteccionista capaz de resguardar o fomento da "produção nacional" de bacalhau por meio de mecanismos de reserva artificial de mercado - sistema de quotas de rateio para condicionar as importações, subvenções de preços e de custo dos factores para proteger e estimular a produção interna.

Construído com largueza de meios, aquele organismo regulador seria dos mais eficazes e duradoiros que o Estado autoritário impôs a pretexto de construir

4 Decreto-Lei no 23 968, de 5 de Junho de 1934. Assinado por António de Oliveira Salazar, presidente do Conselho de Ministros, e por Sebastião Garcia Ramirez, ministro do Comércio e Indústria. O escrito académico de Salazar a que nos referimos, "Alguns aspectos sobre a crise das subsistências", foi publicado pela primeira vez no Boletim da Faculdade de Direito da Universidade de Coimbra, em 1918, e pode ser lido numa reedição recente, enriquecida com notas e comentários. Vide Nuno Valério (introd. e org.), António de Oliveira Salazar - O Ágio do Ouro e outros textos económicos (1916-1918), Lisboa, Banco de Portugal, 1997, pp. 223-275. 
uma "economia nacional corporativa". Nada corporativa, mas puramente estatal, a CRCB quase não sofreu alterações no seu figurino institucional até ao soçobrar da ditadura de Salazar e Caetano. Máquina pesada e bem dotada de recursos humanos e técnicos para a prática de comércio de Estado, ironicamente nem a Revolução de Abril de 1974 ou sequer os governos da transição democrática a extinguiram. A contrário, os organismos da "estrutura corporativa" das pescas que, desde 1936, dependiam do patronato político de Henrique Tenreiro (delegado do Governo junto dos organismos das pescas, mas nunca ministro ou secretário de Estado ${ }^{5}$ ), foram extintos de um sopro em 1974 - grémios, sindicatos corporativos e, antes dos demais, a poderosa Junta Central das Casas dos Pescadores, baluarte da "obra social das pescas" promovida pelo Estado Novo, cujo arquivo em boa parte se perdeu.

Situada em território diverso e nunca conotada com o império de poderes do almirante Tenreiro, a CRCB sobreviveu à queda da ditadura salazarista e, por ironia, tomou um papel de relevo na substituição de um modelo de economia dirigida de sugestões corporativas por outro, de inspiração socialista. No Verão de 1974, no tumulto especulativo e inflacionário em que se vivia, a Comissão Reguladora foi incumbida de fazer intervenção directa no mercado português e internacional, tomando então uma feição empresarial que a doutrina corporativa sempre lhe recusara.

A extinção que mais importa a este debate foi a do Grémio dos Armadores de Navios de Pesca do Bacalhau, organismo corporativo de carácter obrigatório que fora criado em 1935 para disciplinar o "capital" e agrupar as empresas de pesca e de secagem ${ }^{6}$. Embora vocacionado para conduzir o fomento das indústrias de bacalhau e para obrigar os armadores a assumirem certos encargos de assistência e previdência com o "trabalho", o Grémio subordinava-se à coordenação da CRCB. Sobretudo nos domínios da política de fomento da frota e em que tudo o que envolvia o problema político do abastecimento de bacalhau.

Sem surpresa, quando foi extinto, no Verão de 1974, o seu grosso arquivo e todos os activos da instituição foram integrados no património da Comissão Reguladora. Quando nos deparámos com o arquivo da CRCB em liquidação, a parte relativa à documentação do extinto Grémio, há muito transferida e

5 Henrique Ernesto Serra dos Santos Tenreiro (1901-1994). Para uma biografia, vide os nossos artigos: "Henrique Tenreiro: patrão das pescas e guardião do Estado Novo", Análise Social, vol. XXXVI, Outono de 2001, pp. 839-862; "Henrique Tenreiro: um empresário do sector público-corporativo da economia salazarista?", Estudos do Século XX, nº 4, 2004, pp. 297-322.

6 Decreto-Lei ${ }^{\circ} 26$ 106, de 23 de Novembro de 1935. Sobre as atribuições institucionais do Grémio e a sua acção no fomento das indústrias do bacalhau, vide A. Garrido, O Estado Novo e a Campanha do Bacalhau, cit., pp. 170-183. 
integrada, mal se distinguia do todo. De corpo mais restrito, parecia, porém, muito valiosa para o estudo da vida interna do Grémio mais poderoso das "pescas corporativas", tanto mais que a colecção de livros de actas das direcções e dos conselhos gerais se encontrava completa e o papel em razoável estado de conservação. Os relatórios e contas do Grémio, da respectiva Mútua dos Navios Bacalhoeiros e da Cooperativa de aprestos (estes últimos muito incompletos) pareciam conter informação abundante, de natureza qualitativa e quantitativa, para analisar e perceber o funcionamento da "estrutura corporativa". Não por acaso, dado que o arquivo do Grémio também continha listas de navios e toda uma memória documental, iconográfica e serial sobre a "frota bacalhoeira portuguesa" - que interessava à preservação de uma memória da "faina maior" " que, no começo da década de noventa, começara a tomar destaque no projecto cultural do Museu Marítimo de Ílhavo -, em Setembro de 1994 registou-se o primeiro acto de transferência de "documentação de arquivo da CRCB" para o referido Museu. Em rigor, a "cessão a título precário", assumida pela "CRCB em liquidação" presidida pelo Juiz Desembargador João Semedo, procedia ao depósito de uma ínfima parte do "arquivo" naquela instituição museológica, cuja comunidade local o auto de depósito classificava de "largas tradições piscatórias".

Os interesses e expectativas de uma e outra parte seriam, com certeza, diversos. Os caminhos da história-memória e da história-ciência começavam a fundir-se e a confundir-se. Compreensivelmente, as preocupações dos actores da liquidação eram muito mais prosaicas. A pequena mas valiosa parcela de documentação confiada ao Museu de Ílhavo tornava-se, sob especiais condições, acessível para consulta. A restante, muito mais ampla, permanecia inacessível, à guarda da comissão liquidatária da CRCB e acondicionada em deploráveis condições numa cave do edifício Pedro Álvares Cabral, na parte administrativa dos antigos e imponentes armazéns frigoríficos da sede da instituição, em Alcântara, Lisboa.

7 Designação similar à expressão francesa “grand métier”, atribuída pelos responsáveis do Museu a uma exposição temporária aberta em 1992 e que acabaria por se tornar permanente. Mitificadora, a expressão "faina maior" remetia para uma memória épica da pesca do bacalhau à linha com dóris, o processo artesanal de produção que apenas terminou em 1974 e cuja aura heróica a propaganda do Estado Novo tanto exaltara, em Portugal e no estrangeiro. Por ironia do tempo e das circunstâncias, no começo dos anos noventa o Museu que mais se propunha conservar essa memória heróica de âmbito local e nacional era o mesmo que se dispunha a acolher a documentação que permitiria estudar e desconstruir as múltiplas ligações da ditadura salazarista ao "ressurgimento da grande pesca". 


\section{O organismo de coordenação económica - vocação institucional, trajectória e arquivo}

Atendendo à natureza burocrática, reguladora e fiscalizadora do organismo, à dimensão patrimonial que adquiriu e às atribuições institucionais com que o Estado (nas suas diversas formas políticas de regime) o dotou até à inevitável extinção, em 1986, não estranha que, por determinação dos seus próprios estatutos, a CRCB tenha organizado um imenso arquivo. Um acervo variado de documentos, depostos segundo uma racionalidade burocrática e fria, ainda evidente quando com ele topámos, com a emoção de quem descobre a pólvora que lhe faltava para a batalha que se propusera travar.

Quando nos deparámos com o arquivo, já o estudo da legislação e de alguma bibliografia sobre o corporativismo salazarista e suas contradições ${ }^{8}$ nos permitira perceber que a CRCB fora criada pelo Estado para realmente funcionar. A fim de conduzir a "campanha do bacalhau" - um programa de autarcia relativa, cujos pilares foram o condicionamento das importações de bacalhau e o fomento da pesca e da construção naval em torno de pequenos clusters regionais -, Salazar não hesitou em amarrar os interesses privados a um projecto "político nacional". Ao chamar a si a regulação autoritária - política, mas legitimada pela técnica, dado o papel dos engenheiros e de médicos veterinários no funcionamento da CRCB - do abastecimento de bacalhau, o Governo declarava-o um problema público que, uma vez solucionado, teria repercussões positivas na imagem de autoridade do Estado. Um Estado novo, discursivamente antiliberal, mas em rigor apenas supra-liberal, visto que os principais enunciados do liberalismo económico nunca foram ameaçados pela "ordem económica corporativa" vertida na Constituição de 1933 ou sequer pela prática da "economia dirigida" e das respectivas instituições.

Por extenso, serial e em boa parte composto por papéis anódinos, resultantes de uma obsessiva cultura de registo, de começo o arquivo que tínhamos diante

8 Destacamos a obra de referência de Manuel de Lucena e uma série de artigos do mesmo autor, respectivamente: A evolução do sistema corporativo português, 2 vols., Lisboa, Perspectivas \& Realidades, 1976; "Sobre a evolução dos organismos de coordenação económica ligados à lavoura”, Análise Social, vol. XIV, nº 56 (I); vol. XV, nº 57, 1979 (II); vol. XV, nº 58, 1979 (III). De acordo com a importância que para nós tiveram na construção de uma grelha (conceptual e prática) de leitura do arquivo da CRCB, salientamos os livros de Vital Moreira, Auto-Regulação Profissional e Administração Pública, Coimbra, Livraria Almedina, 1997; Philippe Schmitter, Portugal: do Autoritarismo à Democracia, Lisboa, Imprensa de Ciências Sociais, 1999; Howard J. Wiarda, Corporatism and Development; the Portuguese Experience, The University of Massachusetts Press, 1977. 
de nós não se dispunha a revelar grandes intrigas. À parte a colecção de "despachos" que não resistimos a vasculhar o quanto antes, com a voragem de quem presumia encontrar alguns "traços de sangue" na grossa correspondência que fora trocada entre os dirigentes do organismo e os ministros da tutela, tudo era demasiado monótono e invariavelmente mecanográfico. Entre os milhares de ofícios e de facturas dactilografados, os livros de actas lavrados a boa caligrafia e os gráficos de propaganda do abastecimento, desenhados a lápis ou pintados a guache com paciência e perfeição, havia um claro denominador comum: estaríamos perante uma verdadeira organização, cujo lastro documental exprimia uma imagem póstuma de racionalidade e eficiência, presumindo a dedicação e competência de um corpo de serviços que, por certo, não haviam frustrado os intentos do legislador.

Embora tais impressões pudessem ser desmentidas pela leitura detida e sistémica de toda aquela mole de papéis - remota miragem que desfalecia o ânimo de lhes aplicar qualquer inquérito vagaroso -, o objecto começava a inquietar o sujeito. Por meio de dúvidas metodológicas mais ou menos previsíveis, e de outras, que ameaçavam tornar-se embaraços de outra sorte.

Como bons democratas e antisalazaristas convictos, estaríamos perante uma prova irrefutável de eficácia do Estado autoritário na superação das fraquezas da República liberal? Seríamos nós, republicanos de alma, impelidos a interpretar uma experiência relevante na história económica e social do período salazarista segundo a indução do próprio registo das instituições?

Nessa fase preambular da investigação, a do mergulho no arquivo, as dúvidas "existenciais" (as do foro da relação ideológica do sujeito com o objecto, problema ainda mais iniludível para um historiador do século XX) pesavam mais no espírito do que o conforto das referências de método e da teoria epistemológica. À medida que a pesquisa progrediu, percebemos que tais questões não eram falsas nem vãs. No desfecho dela, a nossa visão da história do Estado Novo não se tornou relativista nem revisionista; apenas muito mais complexa e desconfiada da visão estruturalista dominante na historiografia da especialidade.

A CRCB foi um organismo público dotado de largos poderes institucionais de direcção de um sector de importância vital para o abastecimento alimentar da população portuguesa da "metrópole" ". Por inerência, foi criada para isolar o Estado da subversão e garantir uma paz social compulsiva, a ideia conservadora

9 Entre 1934 e 1974, Portugal exportou para as colónias quantidades ínfimas de bacalhau, em regra destinadas à população branca. Os poucos fardos que seguiam para consumo das populações locais eram, por norma, de tamanhos pequenos e de cura imperfeita. 
a que Salazar terá subordinado uma economia política dirigista, povoada de instituições de enquadramento vertical e horizontal dos interesses ${ }^{10}$.

Dados os fins políticos para que foi talhada, não espanta que a $\mathrm{CRCB}$ pouco tenha mudado durante o regime que a imaginou e impôs. Porém, como denunciou a própria organização do arquivo que compulsámos, ao longo dos seus 52 anos de existência o organismo conheceu variações de sentido que podemos ordenar em quatro ciclos diferenciados da sua vida institucional: a) Entre a criação da CRCB, em 1934, e a liberalização do comércio de bacalhau, em 1967 - o termo prático e simbólico da "campanha do bacalhau"; b) Da liberalização das importações e dos preços, em Julho de 1967, à Revolução de 25 de Abril de 1974; c) Do tumulto revolucionário à extinção do organismo, em 12 de Agosto de 1986, na sequência da adesão de Portugal à Comunidade Económica Europeia; d) O longo processo de liquidação, concluído em finais de 2001, e o destino do "património documental" do velho organismo.

a) O perfil institucional da CRCB, desenhado pelo decreto criador de 5 de Junho de 1934, apontava para um "organismo de intervenção económica" de pura feição estatal. Talvez porque tal figurino inibia, à partida, a construção de um "corporativismo associativo" neste sub-sector da "economia nacional", o DL n 27 150, de 30 de Outubro de 1936, fazia uso da retórica doutrinal considerando a CRCB um "organismo pré-corporativo", isto é, de provável extinção quando sobreviessem as corporações previstas como cúpula do sistema (corporativo) de ordenamento da vida económica e social.

Na opção governamental por um corporativismo autoritário, estatal e plasmado numa organização que, $a b$ initio, se erguera em forma de pirâmide invertida, o mesmo Decreto precisava o estatuto jurídico da CRCB. Em obediência à legislação que o ministro Pedro Teotónio Pereira ${ }^{11}$ entretanto publicara para acertar o perfil da miríade de organismos que o Estado já impusera a diversos ramos da agricultura, do comércio e da indústria - Comissões Reguladoras,

${ }^{10}$ Vide Fernando Rosas, O Estado Novo nos Anos Trinta. Elementos para o estudo da natureza económica e social do salazarismo (1928-1938), Lisboa, Estampa, 1994; Nuno L. Madureira, A Economia dos Interesses, Lisboa, Livros Horizonte, 2002.

${ }^{11}$ Ministro do Comércio e Indústria, 18.1.1936-13.12.1937. Antes de se ocupar dessa pasta ministerial, P. Teotónio Pereira foi subsecretário de Estado das Corporações e Previdência Social (11.4.1933-3.1.1936). Em 1937, Salazar fê-lo embaixador na Espanha franquista. Para uma biografia, vide Fernando Martins, Pedro Theotónio Pereira: uma biografia (1902-1972), Évora, Universidade de Évora, 2005 (dissertação de Doutoramento em História, policopiada) e Manuel de Lucena, "Pedro Teotónio Pereira", Dicionário de História de Portugal, vol. IX, "Suplemento" (dir. A. Barreto e M. Filomena Mónica), Porto, Figueirinhas, 2000, pp. 43-60. 
Juntas e Institutos -, a CRCB era classificada como "organismo de coordenação económica".

Nos novos termos da lei, o Estado cometia ao organismo as seguintes funções oficiais: regular as condições de abastecimento do "mercado nacional", condicionando as importações e garantindo a colocação do bacalhau pescado por navios portugueses; fiscalizar e orientar todos os segmentos de comercialização, procurando conter os preços e normalizar os processos de cura; dirigir e condicionar as políticas de renovação da frota pesqueira, observando o escrutínio das necessidades do provimento; zelar pelo aperfeiçoamento técnico nos aspectos da preparação e conservação do peixe; constituir e gerir as reservas necessárias ao abastecimento do "mercado nacional", fazendo bom uso dos armazéns frigoríficos a construir nos principais centros de consumo.

Dotada de poderes oficiais para negociar colectivamente as importações e fazer diplomacia económica nos principais centros exportadores (Noruega, Terra Nova e Islândia), a CRCB depressa se tornou o maior comprador de bacalhau a operar no mercado internacional. Até 1941, o poder negocial do organismo português fez descer as cotações externas do produto. Em 1938 já a CRCB se convertera num arquétipo da pretensa superioridade da fórmula salazarista de intervenção em sectores estratégicos da "economia nacional", antes subordinados aos interesses e práticas do capitalismo liberal, segundo as vulgatas de propaganda da obra do regime.

Em síntese, tratava-se de um organismo dotado de amplos poderes de coordenação do provimento de bacalhau em todos os seus segmentos de circulação - da produção no mar ao comércio de retalho. Adaptado das normas de contabilidade pública, o regime financeiro da CRCB era muito flexível do lado da receita e na gestão dos "fundos especiais", cuja movimentação apenas dependia de despacho do ministro da tutela (Ministério do Comércio e Indústria, depois da Economia). O regimento admitia a cobrança de taxas sobre as transacções de bacalhau que permitiram ao organismo regulador dotar-se de meios técnicos modernos e de amplos armazéns refrigerados que serviram para gerir o provimento de diversos bens alimentares agrícolas. O mapa de pessoal da $\mathrm{CRCB}$, qualificado e capaz de executar com eficácia a gestão política do abastecimento, cresceu até finais da década de cinquenta. Em 1957 contava 432 funcionários.

b) Entre 1967 e 1974 os poderes institucionais da CRCB alteram-se e confinam-se a um âmbito mais restrito. A Portaria $\mathrm{n}^{\circ} 22$ 790, de 22 de Julho de 1967, quase um epitáfio político da "campanha do bacalhau" assinado pelo secretário de Estado do Comércio, Fernando Alves Machado, com aval do ministro da Economia, Gonçalo Correia de Oliveira, punha termo aos principais baluartes proteccionistas da "campanha do bacalhau": abolia a tabela de preços e permitia 
aos armazenistas a importação a título individual. Tais medidas liberalizadoras, longamente ponderadas no âmbito da Comissão de Coordenação Económica do Ministério da Economia desde 1958, resultaram de dificuldades de tesouraria do Fundo de Abastecimento - espécie de "saco azul" criado em 1947 pelo ministro Daniel Barbosa para financiamento do sistema de preços políticos-e, em menor parte, das obrigações que Portugal assumira ao aderir à EFTA, em 1960. Previsivelmente, a liberalização das importações e a abolição da tabela descontrolaram o abastecimento, fizeram recrudescer a especulação e resultaram numa acentuada subida dos preços de mercado.

Embora conservasse o licenciamento e o registo prévio das importações, mercê da liberalização do comércio a CRCB deixou de funcionar como simples organismo coordenador e passou a intervir mais directamente no mercado por meio de operações comerciais de importação autorizadas pelo Governo. De organismo coordenador do "cartel corporativo" dos armazenistas importadores e do próprio Grémio dos Armadores, a CRCB passava a "cartel de Estado", em acesa concorrência com os agentes privados.

Em Abril de 1974, o mercado português era dominado por oligopólios de importadores cujo negócio se reforçara desde que a produção interna se retraíra; quer devido a restrições jurídicas ao exercício da pesca em águas exteriores, quer devido aos efeitos da "crise do petróleo" de 1973 sobre as empresas armadoras de pesca longínqua.

c) De 1974 a 1986 acentua-se a feição mercantil da CRCB, cuja actuação cada vez mais se assemelha à de uma empresa pública investida de poderes oficiais de intervenção no mercado. Num primeiro momento, os governos provisórios saídos da Revolução procuram conter as perturbações do abastecimento anulando certas disposições da liberalização de 1967. Num período de fortíssima especulação, a CRCB recupera por lei o exclusivo das importações que tivera entre 1934 e 1967 e passa a distribuir o bacalhau directamente pelo comércio grossista e de retalho, conforme as normas que a tutela vai fixando a fim de garantir o controlo de preços. Mais intervencionista do que nunca, o velho organismo opera no mercado como grande importador e alarga o negócio ao segmento dos congelados. Quando seria de esperar que soçobrasse, durante o PREC a CRCB reabilita a sua importância política e social. O frágil reforço provém de factores internos e de ordem exterior: resulta da conjuntura inflacionista e da incerteza do abastecimento alimentar; e da mudança abrupta do Direito do Mar, cuja expressão maior se acolheu no movimento de criação de Zonas Económicas Exclusivas, conceito que Portugal subscreveu na III Conferência das Nações Unidas, em estreita convergência com os países afro-asiáticos. 
Agitada por processos políticos, convulsões internas e sindicâncias, a CRCB reconquistou uma certa estabilidade durante o período constitucional que se seguiu a 1976. Na abertura dos anos oitenta, o Estado começou a ponderar a extinção do organismo. O primeiro passo foi dado em Outubro de 1983, no âmbito dos trabalhos da Comissão Interministerial para os Mercados de Produtos Alimentares. Continuando a deter o monopólio das importações de bacalhau e prolongando alguns dos velhos esquemas de intervenção estatal no funcionamento do mercado, o perfil da CRCB tornara-se incompatível com o disposto na legislação comunitária em matéria de comércio (o Tratado de Roma de 1957 e o Tratado de Adesão de 1 de Janeiro de 1986).

Através do $\mathrm{DLn}^{\circ}$ 224/86, de 12 de Agosto, o Governo determinava a extinção da CRCB. Para a consumar, era criada uma comissão liquidatária incumbida de dar destino ao imenso património do organismo, de realizar o activo e liquidar o passivo. A sensatez dos administradores liquidatários permitiu ao Estado reconhecer no arquivo do organismo um activo de intangível valor, susceptível de ser realizado por outros modos que não os da venda a uma qualquer empresa farrapeira.

d) A extinção da CRCB deixara antever uma nova era de desregulação do mercado português de bacalhau. Com o aperto das áreas de pesca no Atlântico Noroeste, a margem de auto-aprovisionamento do mercado interno voltara a ser escassa e o atraso das redes de frio retardava a sua conquista por produtos substitutivos do bacalhau salgado seco.

Ponderando estas e outras vicissitudes, o legislador achou prudente compensar a extinção do antigo organismo regulador com uma empresa de capitais públicos vocacionada para o comércio, importação e exportação de produtos da pesca - a trading "CRCB - Companhias Reunidas de Congelados e Bacalhau, S.A.."" . Na prática, desconfiado das capacidades do mercado para se auto-regular e ciente da "experiência" e "credibilidade"13 do organismo que era forçado a extinguir, o Estado democrático criava uma empresa sucedânea da CRCB na expectativa de evitar a perda de poder negocial nos mercados externos. À semelhança de tantas outras empresas públicas da fileira da pesca nas quais o Estado nunca conseguiu interessar capitais privados, a CRCB S.A. depressa evidenciou uma estrutura operacional desajustada do crescimento do sector privado no domínio da comercialização de pescado. Perante o agravamento

${ }^{12}$ Esta empresa de capitais públicos foi criada através do Decreto-Lei n ${ }^{\circ} 225 / 86$. No mesmo dia (12 de Agosto) em que o diploma homólogo $\mathrm{n}^{\circ} 224$ extinguiu a CRCB e anunciou a sua liquidação.

${ }^{13}$ Ambos os qualificativos constam do preâmbulo do referido Decreto-Lei no 225/86, de 12 de Agosto, assinado pelo Primeiro-Ministro Aníbal Cavaco Silva. 
da situação financeira da empresa e a dificuldade em rentabilizar os capitais colocados à sua disposição, apesar dos diversos apoios e avales do Tesouro, a trading foi dissolvida em meados de $1997^{14}$.

Corria então, morosamente, o processo de liquidação da CRCB.

Memória de uma "economia corporativa" que nunca existiu, a CRCB teve uma vida longa, estável e folgada. A sua longevidade, dimensão e eficácia tornaram-na resistente à mudança política e fizeram da extinção um interminável processo. Por afortunada ironia, a demora foi propícia à "descoberta" e salvaguarda do arquivo, cuja decisão de destino fez parte do próprio processo liquidatário.

Através do Decreto-Lei n ${ }^{\circ}$ 28/99, de 29 de Janeiro, a última peça legislativa desta história, o Ministério das Finanças aduzia três razões de peso para justificar o atraso da liquidação que fora iniciada a 12 de Agosto de 1986: 1) "Dado o valor do activo ser insuficiente para cobrir o passivo existente, correspondente à constituição das necessárias reservas matemáticas à Caixa Geral de Aposentações"; 2) "Face ao avultado arquivo, quer de natureza corrente, quer de cariz histórico, da CRCB, importa igualmente determinar o seu destino". A terceira reportava-se à necessidade de transferir para o Estado (Direcção-Geral do Tesouro) as acções judiciais em que a CRCB fosse parte. Concretizando as explicações do preâmbulo, quanto aos "arquivos" o diploma assinado por António de Sousa Franco determinava que "toda a documentação histórica" seria "afecta ao Museu Marítimo e Regional de Ílhavo"15.

\section{O arquivo da CRCB - meta-fontes e memória documental da "economia dirigida"}

Quando, em Janeiro de 1998, obtivemos da Direcção-Geral do Tesouro autorização de consulta do espólio documental da CRCB, concedida na base de um parecer do administrador liquidatário, Dr. Fernando Patronilo d'Araújo, tivemos a sensação exagerada de que nos fora autorizado entrar numa caixa-forte repleta de papéis mais e menos confidenciais, mas todos relativos a "assuntos de Estado".

Durante o Inverno e parte da Primavera desse ano, com o precioso auxílio do único funcionário que transitara do Grémio da Pesca do Bacalhau, o Sr. Esmeraldino Pais Domingos - ele próprio uma excelente fonte, pela sua prestimosa disponibilidade para nos contar o antes e o depois da vida interna do Grémio e da própria Comissão Reguladora -, tivemos que proceder ao inventário de

\footnotetext{
${ }^{14}$ Decreto-Lei $\mathrm{n}^{\mathrm{0}}$ 151-A/97, de 18 de Junho.

${ }^{15}$ Art. $2^{\circ}, 2$.
} 
boa parte da documentação. Embora laborioso e preciso, o trabalho da entidade produtora do "arquivo", os serviços de secretariado da CRCB, não fora suficiente para legar um índice que ainda se lesse.

$\mathrm{Na}$ cave húmida e sombria a que fôramos conduzidos para avistar, pela primeira vez, o "arquivo em abandono", jaziam, de facto, centenas de arquivadores atestados de folhas amarelecidas, alguns maços de facturas e inúmeros livros de registo. Mas ali estavam, também, milhares de papéis fora de sítio, recobertos de sal que sobrara dos armazéns refrigerados onde, durante décadas, os dirigentes do extinto organismo haviam mandado reter o bacalhau à espera de ordem para o lançar no mercado. Por ironia, o sal que conservara o bacalhau nos porões dos navios da frota bacalhoeira e que, em menores porções do que a bordo, também se usara para acamar o bacalhau no grande armazém onde estávamos, ameaçava deteriorar toda aquela documentação. Por impossibilidade de trabalhar ali - apesar das agruras ambientais, o trabalho de historiador sempre se quer menos violento que os da pesca e da estiva -, e por amável sugestão do Dr. Patronilo, as pastas que presumimos de maior importância foram deslocadas para o terceiro andar do edifício, onde havia outros papéis de "valor histórico" e o ar circulava em correntes favoráveis à secagem das pastas envoltas em salmoura que trouxéramos da cave. Com argúcia e bom humor, o Sr. Domingos lembrava que o sal e o vento sempre haviam sido elementos indispensáveis ao ciclo produtivo do bacalhau; por isso, estaríamos apenas perante duas irónicas coincidências, havendo que fazer bom uso delas para conservar o próprio arquivo.

Procurando vencer os obstáculos mais insólitos, mas contando com a extraordinária solicitude e sensibilidade do Sr. administrador liquidatário, não foi necessário persuadi-lo das vantagens em propor à tutela a transferência de toda a documentação para o Museu de Ílhavo, onde já se encontrava em depósito uma parte dos fundos documentais do extinto Grémio dos Armadores.

À época, não tínhamos ainda qualquer ligação com o Museu. Os argumentos mais óbvios para a transferência dos papéis eram os de evitar a sua fragmentação e de prevenir a inviabilidade de acesso. Argumentos secundários, mas igualmente importantes, seriam a vocação temática do Museu, cada vez mais marítimo e cada vez menos votado ao velho discurso etnográfico sobre "os usos e costumes locais", e o compromisso da instituição em proceder ao inventário e catalogação daquele imenso fundo documental.

Volvidos sete anos do primeiro acto de transferência oficial do espólio, de que fomos testemunha a 29 de Outubro de 1999, a opção de destino do "arquivo" da CRCB ainda hoje nos parece a mais certa, embora perturbada por atrasos no tratamento do espólio. $\mathrm{O}$ facto acidental de termos assumido a direcção do 
Museu em Janeiro de 2003, acresce as nossas responsabilidades num processo de liquidação, transferência e incorporação, que conhecemos quase desde o início. Por enriquecedora que seja essa coincidência - em Portugal muito rara, dado que poucos historiadores têm experimentado o papel de construtores de memórias em contextos museológicos -, ela só será bem sucedida se, dentro em breve, o Museu conseguir os recursos indispensáveis para disponibilizar on-line a pesquisa dos fundos de arquivo da CRCB e do Grémio no âmbito do "Centro de Documentação sobre a Pesca do Bacalhau" que o seu Regulamento prevê.

Não sendo muito comum que os Museus portugueses, quer os tutelados pelo Ministério da Cultura, quer os municipais, assumam valências de arquivo histórico, no caso em apreço essa dimensão é estruturante do perfil cultural do Museu e do seu projecto de activação patrimonial das memórias sociais da "grande pesca". Além disso, visto que a pesca do bacalhau se pode classificar como um "facto social total", cremos que a construção de narrativas museológicas sobre o fenómeno só será um processo aberto e plural se os avatares da história-memória e da história-ciência se combinarem, num processo mútuo de revisão crítica. Se é certo que a viva voz dos actores da última aventura dos portugueses no mar - impelida por um regime ditatorial, mas uma indiscutível e admirável saga que, por significativa coincidência, só terminou quando a ditadura soçobrou - será sempre a primeira fonte para a elaboração de discursos expositivos sobre a "faina maior", não será menos provável que essa construção possa beneficiar do estudo das fontes e meta-fontes contidas nos fundos documentais da CRCB e do Grémio.

Todavia, seja em sede museológica, seja em contextos académicos de produção historiográfica, o uso deste género de "arquivos" sugere algumas cautelas epistemológicas. As ilusões de abundância e o encantamento com a totalidade são impressões comuns que, em regra, persuadem o historiador da racionalidade burocrática do organismo e da tremenda eficácia do Estado que o criou. Além disso, as sugestões probatórias da documentação dominante - relatórios, boletins, estatísticas, ofícios e actas - exigem redobradas atenções com a intencionalidade das fontes, com a sua operacionalidade no contexto interno da instituição em que foram produzidas e com os próprios destinatários do discurso vertido nos documentos. Para reforço destas precauções, bastará recordar o enunciado conceptual de Michel Foucault, segundo o qual um "arquivo" é, por natureza, uma formação discursiva ${ }^{16}$. Quando se trata de fundos documentais que, no essencial, são agregados de meta-fontes que presumem o

${ }^{16}$ Cfr. Michel Foucault, A Arqueologia do Saber, Coimbra, Almedina (trad.), 2005, pp. 7-26 (António Fernando Cascais, "Nota de Apresentação"). 
legado consciente de uma instituição que foi parte de um Estado autoritário, a prevenção de Foucault torna-se ainda mais pertinente.

Quando se trata de estudar as relações entre o público e o privado nos regimes autoritários e totalitários do período entre as guerras, como recorda Nuno L. Madureira num breve excurso sobre "fontes e investigação", "a principal consequência é a historicização das justificações" ${ }^{17}$. O mesmo autor alerta para a necessidade de, perante esse tipo de fontes, ser indispensável cruzá-las com diferentes tipologias de informação, multiplicando as escalas de análise e submetendo à crítica as perspectivas dos próprios emissores de discurso ${ }^{18}$. Na nossa experiência concreta, a procura de um equilíbrio entre documentação agregada e desagregada e o confronto das fontes produzidas por organismos portugueses (CRCB e Grémio) com as dos estrangeiros (cartéis de exportadores do Canadá) complexificou a análise e as interpretações ${ }^{19}$.

Neste como noutros casos, os arquivos e o discurso que encerram não exprimem processos mudos. Antes uma pletora de significados que importa examinar sem presumir que os actores privados foram esmagados pelas estruturas institucionais. Nesta como em toda a História, o maior risco estará sempre em banir o Homem do seu palco.

\section{Arquivos de instituições económicas do salazarismo e propostas de investigação}

A título de reflexão final, fazendo uso da experiência concreta a que nos reportámos, será oportuno pôr em evidência algumas conclusões e, a partir delas, enunciar uma proposta de investigação na área abrangente (e pouco precisa) da "história do Estado Novo". A pequena agenda que sugerimos não é indefinidamente aberta, mas circunscrita à prospecção de arquivos de instituições económicas e, talvez mais importante, a uma epistemologia dos próprios arquivos de instituições corporativas e de coordenação económica.

Como têm salientado diversos historiadores, as atenções e os esforços de prospecção, tratamento e disponibilização para consulta de corpos documentais relativos ao período salazarista (1926-1974), têm conferido um claro privilégio à "história política". Sendo certo que esta classificação se torna ainda mais

${ }^{17}$ Nuno L. Madureira, ob. cit., p. 13.

${ }^{18}$ Id., ibidem.

${ }^{19}$ Desse exercício resultou o seguinte artigo: A. Garrido, "Political Economy and International Trade: The Portuguese Market for Salt Cod and Its Institutions in the Interwar Period", International Journal of Maritime History, vol. XVII, $\mathrm{n}^{\mathrm{o}}$ 2, December 2005, pp. 61-85. 
redutora quando se trata de estudar um regime que à política (ou à batalha da sua própria durabilidade, como lembra Fernando $\operatorname{Rosas}^{20}$ ) subordinou a vida económica e social, também é verdade que poucos autores têm atribuído relevo à história das instituições. Referimo-nos a tomar a "história das instituições" como um campo relativamente autónomo de estudo, visto que há consenso sobre o facto de o Estado Novo ter sido construído por meio de uma "revolução legal" e institucional - tese que Manuel de Lucena provou até à exaustão.

Terreno menos atractivo, porventura menos dado aos apelos do mercado de publicações no campo fértil da memória histórica contemporânea, a "história das instituições" poderá emprestar às grandes sínteses historiográficas sobre o Estado Novo algumas novidades. Neste nosso esboço não consideramos as instituições políticas propriamente ditas (Presidência da República, Conselho de Ministros, Assembleia Nacional e outras, constitutivas de um sistema político sobre o qual já se publicaram muitos estudos), nem nos cingimos a instituições económicas e financeiras (Ministérios da Economia e das Finanças, Conselho Técnico Corporativo, Comissão de Coordenação Económica e tantas outras). Antes a uma extensa plêiade de instituições que foram parte de um território híbrido (ou espúrio, numa análise mais fina) a que podemos chamar o "sector público-corporativo da economia salazarista".

A expressão não está isenta de debate nem deixará de ser ambígua. Mas será claramente preferível e mais rigorosa do que as alternativas "economia corporativa" ou "sector corporativo da economia portuguesa". É conhecido o facto paradoxal de o intervencionismo do Estado Novo no domínio económico nunca ter consentido a formação de um expressivo sector público da economia. Tal verdade parece-nos, todavia, apenas formal. Se uma equipa de historiadores se prestar ao trabalho de identificar e cartografar todos os organismos corporativos e de coordenação económica que foram criados a partir de 1926 no sentido de os agrupar por sectores e ramos da actividade económica e lhes medir a expressão do emprego que criaram, talvez se lhe depare uma imensa realidade, um terreno fértil em perguntas de investigação.

Cremos que a única forma de aferir a dimensão e os papéis desta economia institucionalizada e os diversos esquemas de intermediação que as instituições estabeleceram entre o Estado e o mercado, será elaborar monografias dos principais organismos, agrupando-os e comparando-os. Previsivelmente, só no final desse exercício selectivo e árduo poderão surgir sínteses capazes de entrar em debate com as pré-existentes e de objecto mais largo.

\footnotetext{
${ }^{20}$ Salazarismo e Fomento Económico, Lisboa Editorial Notícias, 2000, pp. 9-16.
} 
Do ponto de vista operacional, a concretização deste projecto mobilizaria um trabalho prévio que, tanto quanto sabemos, nunca foi levado a efeito: proceder a uma prospecção do paradeiro e do estado de conservação dos espólios do presumido mapa de organismos e, em articulação com os Arquivos Nacionais da Torre do Tombo ou arquivos de outra natureza, desenhar um plano de incorporação e de inventário integrado no próprio projecto de investigação.

Uma das maiores dificuldades deste programa estaria na identificação do itinerário dos organismos e do seu património documental. Neste ponto, o caminho mais previsível para o achamento ou para se presumir que tudo se perdeu é contrário ao do tempo linear: caminhar do presente para o passado, por dentro dos ministérios onde é suposto haver memória sobre as instituições e acerca dos respectivos processos de liquidação, pode conduzir ao "arquivo" e a ponderar sobre o seu destino.

Num momento em que o vulgo político tornou a palavra "corporativismo" uma noção hiper-referencial da "sociedade portuguesa" e dos pretensos vícios das organizações que compõem a sua malha, seria oportuno revisitar o tema, mas fazê-lo com o rigor de análise com que os historiadores gostam de cultivar o imaginário do seu próprio ofício. Não tanto por impulso deste argumento "presentificado", mas porque a problemática do "corporativismo português" foi das primeiras a despertar, numa perspectiva comparada, o interesse de uma historiografia estrangeira sobre o "fascismo português".

No começo dos anos setenta, Manuel de Lucena foi percursor deste caderno de investigação. Por intuição de prioridade, por formação pessoal ou devido a contingências de método - investigou e escreveu no exílio -, escolheu o estudo do "sistema" e só mais tarde mergulhou nas instituições do sector agrícola - da "lavoura".

Na década de oitenta, José Maria Brandão de Brito e Carlos Bastien elegeram a teoria económica do corporativismo como campo favorito ${ }^{21}$. No caso do primeiro, porque a reconhecera indispensável ao entendimento das políticas de condicionamento industrial do Estado Novo.

Nesta "terceira vaga" historiográfica, seria útil escavar mais abaixo e ligar os três elos da cadeia: doutrina e leis (o sistema); ideias económicas (a teoria); organismos (as instituições).

${ }^{21}$ Vide, respectivamente, A Industrialização Portuguesa no Pós-Guerra (1948-1965). O Condicionamento Industrial, Lisboa, Publicações Dom Quixote, 1989, pp. 33-69; 91-109; Para a história das ideias no Portugal Contemporâneo - a crise dos anos 1945-1954, vol. I, Lisboa, UTL - Instituto Superior de Economia, 1989 (dissertação de Doutoramento, mimeografada), em especial pp. 256-289. 